This is a self-archived - parallel published version of this article in the publication archive of the University of Vaasa. It might differ from the original.

\title{
Expatriation, alcohol and drugs : antecedents and consequences of substance use in expatriation
}

Author(s): Wurtz, Olivier

Title: $\quad$ Expatriation, alcohol and drugs : antecedents and consequences of substance use in expatriation

Year: $\quad 2018$

Version: Accepted manuscript

Copyright C)2018 Emerald Publishing Limited. This manuscript version is made available under the Creative Commons AttributionNonCommercial 4.0 International (CC BY-NC 4.0) license, https://creativecommons.org/licenses/by-nc/4.0/

\section{Please cite the original version:}

Wurtz, O., (2018). Expatriation, alcohol and drugs : antecedents and consequences of substance use in expatriation. Journal of global mobility 6(3-4), 316-334. https://doi.org/10.1108/JGM-o8-2017-0035 


\section{Expatriation, Alcohol and Drugs:}

\section{Antecedents and Consequences of Substance Use in Expatriation}

Purpose - Expatriation is known to be stressful. The present study examines stress as an antecedent of substance use during expatriation and related effects on expatriates' work adjustment. Moreover, the study sheds light on individual-level moderators (i.e. gender and prior international experience) and organizational-level moderators (i.e. organizational social support) that might condition the stress substance use link.

Design/methodology/approach - This work adopts a quantitative survey approach. It is based on two studies, one of 205 expatriates and one of 96 expatriate-supervisor dyads. The data were collected through personal networks and with the help of multinational companies.

Findings - This research shows that stress at a medium to high-level increases substance use among male expatriates, but not among female expatriates. Expatriates with substantial prior international experience were identified as being more prone to react to stress by resorting to substance use. It also provides evidence that substance use to aid coping harms professional adjustment. Moreover, some implications relating to professional adjustment are discussed.

Research limitations/implications - Substance use was self-reported; this may have deterred users from accurately reporting their consumption levels. Moreover, convenience samples have been used. Preventive actions limiting substance use, such as well-being programs, could be sponsored by local human resources managers in order to limit this phenomenon.

Originality/value - This work is one of the first to analyze substance use among expatriates. It shows that some expatriates are more at risk than others of resorting to such use to cope with the hardships of expatriation. 
Adjustment to new and foreign environments is challenging, especially for expatriates who often face isolation (Haslberger et al., 2014, Tung, 2004) brought about by being far from home. It is all the more difficult as the local culture and often the language are different from the expatriate's own. Being in a new, unknown environment creates uncertainty (Black et al., 1991): uncertainty about local reactions, uncertainty about the consequences of their behavior and uncertainty regarding the future. Navigating a new, uncertain, and often difficult to understand environment can be highly stressful. Unsurprisingly, stress levels are likely to be higher among expatriates than among workers remaining at home (Anderzén and Arnetz, 1997). More generally, the multiple issues arising from a move abroad, adjustment, and the uncertainty surrounding a new professional and private life abroad (Black et al., 1991) and also the potential for high levels of stress associated with those factors can lead to a premature return to the home country, disappointing professional performance, marital issues, or psychological troubles (e.g., Harvey and Moeller, 2009; McNulty, 2015; Tung, 1987). This exposure to stressors and the related strain can increase expatriates' propensity to consume substances (Conger, 1956). Indeed, alcohol and drug consumption are often seen as a way to reduce tension, even if only momentarily and artificially (e.g., Belogolovsky et al., 2012). The hardships mentioned above are generally not easily overcome, and some expatriates tend to be prone to such a usage pattern and to the resultant effects (Anderzén and Arnetz, 1997).

Substance use (SU) as used here encompasses the consumption of alcohol or drugs. Drugs include prescription drugs such as antidepressants, sleeping pills, and any other prescribed medication but also proscribed substances such as cocaine. The term SU also does not illustrate the quantity used, so would for example, encapsulate an occasional low-alcohol beer and regularly drinking spirits to excess. This work thus intends to shed light on expatriate substance use. It examines how stress increases SU, and how individual-level and organizational-level factors moderate that relationship, and also highlights the related effects on expatriate work 
adjustment. Improving the understanding of SU by expatriates is important primarily for expatriates themselves. Individuals using substances can jeopardize not only their position and progress within their company but their personal life and health. Understanding SU is also important for organizations because staff whose performance is adversely affected by SU can harm the company's performance too. For employees faced by the challenges of working abroad, excessive SU can reduce the energy and the awareness they can direct at overcoming those challenges (Galaif et al., 2001). Moreover, assigned expatriate positions often confer seniority, and with that comes responsibility (Doherty et al., 2011; Jokinen et al., 2008), and issues among senior expatriates can damage an organization's reputation and expose it to extensive costs. An example would be inappropriate behaviors displayed with locals, ranging from expatriates not dedicating the energy and the effort to adjust, to being under the influence of illegal drugs during these exchanges.

A couple of studies have shown that expatriates consume more substances than domestic employees. In a clinical longitudinal study, Anderzén and Arnetz (1997) monitored alcohol and cigarettes consumption among a group of expatriate employees and used a control group of domestic employees. The research reported that alcohol and cigarette consumption increased dramatically among the expatriates in the first year abroad. The finding is supported by the results of Truman et al. (2011) relating to a group of American expatriates indicating that alcohol and drug use increase during expatriation, leading to a disproportionate number of moderate to high-level substance disorders compared to their domestic employee counterparts. Dr. Margaret McCann, director at Castle Craig Hospital in Scotland states, "the frequent entertaining of clients, colleagues, and other expatriates in the absence of stabilizing influences, which at home exert a restraining influence" can play a role in expatriate SU (Pascoe and Mozer, 2009:2). Specific aspects of expatriation call for the study of SU in such settings.

However, leaving aside the fact that SU is greater during expatriation than at home, there 
is a lack of knowledge regarding alcohol and drug consumption when working abroad. There is a dearth of knowledge on what causes the growth in SU abroad in terms of both trigger factors and which types of person are prone to SU, and also on the consequences of SU among expatriates abroad. This work aims to improve the understanding of SU in expatriation settings. Such knowledge could be key to effectively limiting substance abuse and providing populations at risk with the relevant support (perhaps delivered through human resources managers). The first aim of this study is to determine the impact of stress on SU during expatriation. The second one is to investigate the role of the various contextual and personal factors likely to influence that relationship: this work explores how context and personal factors influence stress-induced alcohol and drugs consumption. The third is to reveal the consequences of SU among expatriate employees.

\section{The influence of stress on SU in expatriation}

Generally, stressful conditions encourage substance use and abuse (e.g., Cooper et al., 1990; Nordlicht, 1979). The tension reduction theory claims that using alcohol or other substances reduces tension and strain and that in stressful situations substances are used to relax and relieve tension (Conger, 1956). The relief experienced might come via various mechanisms such as reducing self-awareness and redirecting the user's attention (Hull, 1981; Steele and Josephs, 1988; Wang et al., 2010). The impact of stress on expatriate SU has not been investigated, however research shows that stress and stressors affect expatriate attitudes both at and outside work (Bader and Berg, 2013; Kraimer and Wayne, 2004; Takeuchi et al., 2005). Tension reduction theory should apply to both domestic and expatriate settings and stressed expatriates should be more likely to consume substances (including but not limited to alcohol) in order to relax and relieve tension, even if only temporarily. In other words, stress is likely to facilitate SU during expatriation. For instance, some expatriates find it hard to fulfil their work 
responsibilities, perhaps because cross-cultural issues make it difficult to elicit appropriate contributions from locals. In parallel, whereas the presence of friends, family, and positive routines usually available in the home country can serve as a safety valve during challenging periods at work, their absence when abroad can contribute to increased stress levels. Consequently, some expatriates are tempted to turn to substances to reduce stress and temporarily induce a sense of well-being.

However, the relationship between stress and SU may be complex: small amounts of stress may be desirable, beneficial, and even healthy (Anderson, 1976). Applying tension reduction theory, stress-induced SU may only come about after the stress/tension reaches a specific level, and at a low level might not be strong enough to trigger an SU response. Curvilinear relationships are rare in expatriate literature, with the exception of some studies that focus on the influence of time (Bhaskar-Shrinivas et al., 2005; Zhu et al., 2016) and antecedents of adjustment (Van Vianen et al., 2004), but some previous research has shown that stressrelated factors can have a curvilinear impact (e.g. Takeuchi et al., 2005, 2007). Research suggests the absence of stress, or the presence of stress at a very low level, can be detrimental to progress. Takeuchi et al. (2005:932) start from the work of Fontaine (1989) and the YerkesDodson Law (Yerkes and Dodson, 1908) and suggest that, "a low to moderate level of workplace stress may work as a motivator to get tasks accomplished." The same study shows that at a low level of psychological strain in the workplace improves job performance. Takeuchi et al. (2007) also provide evidence of stressors having a non-linear influence on adjustment. Similarly, another research calls for the study of the curvilinear influence of stress in challenging situations such as organizational change, suggesting that "a specific amount of stress could actually be beneficial during organizational change" (Amiot et al., 2006). Conversely, it is proposed that low level stress can constrain dysfunctional behaviors such as SU, and expect that at a medium to high level, stress encourages SU. 
H1: Stress displays a curvilinear impact on SU, such that at a low level of stress the influence of stress on SU is negative, while at a medium to high level of stress the influence is positive.

\section{Protective/ vulnerability factors}

Extensions of tension reduction theory indicate that various factors increase or mitigate the risk of stress-induced SU (Cooper et al., 1988; Frone et al., 1995; Wang et al., 2010). The consumption of substances to alleviate the tension generated by stress is unlikely to be uniform across situations and individuals: boundary conditions are key in the relationship between stress and SU and in the application of tension reduction theory (Lui et al., 2009). Moderators that mitigate or strengthen the impact of stressors or stress have been observed in the expatriation context. For instance, perceived assignment value mitigates the negative impact of role novelty on pay satisfaction (Shaffer et al., 2013). Likewise, the impact of stress on SU varies for different people and situations (Cooper et al., 1988; Cooper et al., 1992). Some people will never consume substances whatever their stress levels, while others will drink or take drugs as soon as they feel even moderately stressed. Context and personal factors moderate stressinduced alcohol and drugs consumption (e.g., Liu et al., 2009). Some factors play a protective role by deterring SU for some people, while others can make strengthen the relationship between stress and SU. What effect an individual expects of substance is one factor: individuals who believe that alcohol relieves stress are more likely to drink to cope (Cooper et al., 1992). The availability of alternative coping responses to SU or the mastery of adaptive coping skills also plays a role: individuals with avoidant coping styles are more likely to drink to cope too (Cooper et al., 1988). This research focuses on three types of factors that are likely to affect 
individual vulnerability to stress-induced SU: organizational social support, experience, and gender. Organizational social support could help expatriates resist resorting to using substances when they are feeling low. The very expatriation-specific factor of expatriation experience should also play a role in SU: global careerists with several previous assignments abroad may react differently to a new foreign assignment than less-experienced expatriates (Mäkelä and Suutari, 2011; Suutari et al., 2014), in that their prior experience should boost their ability to adjust to the circumstances and therefore to control stress, thus making them less vulnerable to behavior such as excessive drinking. Finally, research on alcohol use in the domestic context has found it to be strongly influenced by the gender of the user.

\section{Organizational social support}

Organizational social support involves providing alternative coping strategies to SU: use of emotional support and use of instrumental support are two responses that can be deployed to cope with hardships (Carver et al., 1989). The application of the tension reduction frame can be weakened by social support: social support acts as a buffer against substance consumption (Cohen and Wills, 1985) and protects the individual from adopting coping responses to stress that could be detrimental (Wills and Cleary, 1996; Gibbons et al., 2010). Perceived organizational support can facilitate well-being by buffering the negative effects of stressors (e.g., Stamper and Johlke, 2003). Because expatriates are often more isolated or have fewer social connections in their host country than in their country of origin, their potential sources of support can be more limited than those available to domestic employees. Organizational social support is therefore likely to be even more impactful than in domestic settings and to help expatriates resist resorting to alcohol or drugs when they are feeling low; consequently, it is expected that: 
H2: The relationship between stress and SU will depend on the organizational social support received by the expatriate. Stress will trigger more extensive SU among expatriates receiving less support.

\section{Experience}

The application of tension reduction theory to expatriation may be restricted by the experience and learning gathered during previous expatriation that can mean expatriates are less at risk of adopting potentially deleterious methods to aid relaxation such as SU. Yavas and Bodur (1999) showed that the expatriates who were well-adjusted to work had the longest prior international work experience. Caligiuri (2000) showed that international life experience correlated positively with adjustment to the host country and Shaffer et al. (1999) found the number of previous international assignments correlated positively with the adjustment to interaction with host-country nationals. Experienced expatriates might be accustomed to reacting positively to difficult situations and adopting less maladaptive responses to stress than expatriates on their first foreign assignment. Experienced expatriates may therefore be less vulnerable to SU. It is therefore expected that the expatriate experience will affect the stress-SU relationship.

H3: The relationship between stress and $S U$ will depend on the individual expatriate experience. Stress will trigger more extensive SU among less-experienced expatriates.

\section{Gender}

Seminal research showed some differences between female and male expatriates, notably in 
how they cope with the challenges associated with expatriation (Tung, 1998). Men favor separation, a method of acculturation focused on preserving one's cultural norms instead of gravitating to those of the host culture, whereas female expatriates are more willing to open up and relate to others (Berry and Kalin, 1995; Tung, 1998). Women are more likely to explore and learn about the host country or to try to acquire local languages (Tung, 2004).

Men and women apply tension reduction mechanisms differently, in that men are more likely than women to seek relief from and respond to stress by drinking (Dawson et al., 2005). In some research, the relationship between stress and SU is non-significant for women but positively significant for men (Cooper et al., 1992). It appears that the belief that alcohol helps a person relax is more widely shared by men than by women (Rohsenow, 1983), which strongly affects the application of the tension reduction theory. Accordingly, because men are more vulnerable to stress-induced SU than women, it is suggested:

H4: The relationship between stress and SU will depend on the gender of the expatriate. Stress will trigger more extensive SU among men.

\section{Consequences of SU in expatriation}

Impaired functioning theory (Newcomb and Bentler, 1988; Kaplan and Demphouse, 1995), holds that substance abuse affects professional lives. Motivation, energy, attention, and health are all harmed (Galaif et al., 2001). "The impairment is caused by the pharmacological effects of substances on various sensory and neurological functions, as well as interfering with health or adaptive psychological functioning and coping" (Galaif et al., 2001:338). For instance, alcohol consumption is positively related to work problems (Mangione et al., 1999), and to absenteeism (McFarlin and Fals-Stewart, 2002); and the use of drugs increases job 
dissatisfaction and job instability (Newcomb, 1988). These negative outcomes of SU are likely to occur in expatriation. Indeed, the heightened demands generated by adjustment issues can make SU even more detrimental in an expatriate professional situation. For instance, communication with and management of locals can be more challenging than at home because of cultural differences and misunderstandings. Work etiquette is often different, and expatriates need to understand and master it if they are to be efficient. Therefore energy, attention, and motivation are even more needed than at home and the limitation of them due to SU are likely to confirm, if not strengthen, the relationships evidenced in domestic settings. However, in some contexts, use of a specific substance may have a more complex impact on professional adjustment. For instance, in Korea ${ }^{1}$ alcohol consumption in a social environment or during meals can facilitate the establishment of business relationships (Kim and Kim, 2008). Nonetheless, at a general level it is suggested that:

H5: SU is negatively correlated with professional adjustment.

The hypotheses are presented Figure 1.

Insert Figure 1 about here

\footnotetext{
${ }^{1}$ We thank an anonymous reviewer for this suggestion.
} 


\section{Method}

Two studies were conducted based on two different data collection rounds to test the abovereferenced hypotheses. Study 1 investigates antecedents of SU, while Study 2 examines SU's outcomes. The sampling strategy involved aggregating corporate cooperation with more informal networks to encompass various types of expatriates. The general selection criteria aimed to include individuals currently working in a country other than their country of origin.

\section{Study 1: antecedents of SU}

The authors identified 100 contacts from among their social or professional networks and asked them to assist with the data collection effort to support this study. The contacts were selected because they had significant expatriate networks, and in most cases because they were or had been expatriates. The contacts were not incentivized monetarily, and 49 agreed to distribute electronic questionnaires (in English) through emails to 749 of their individual contacts. Ultimately 205 usable responses were received, giving an overall response rate of $27 \%$. Those 205 respondents work in 34 different host countries located in Europe, America, Asia, Africa, and Oceania. The most commonly represented were Germany (13\%), France (13\%), the United Kingdom (10\%), the USA (7\%), and Australia (7\%). The expatriates are mainly French (65\%) but come from 32 different countries in total. Among them, 58\% of respondents are male; $70 \%$ are self-initiated expatriates; and $30 \%$ were sent to work abroad by their organization. Expatriates were aged from 22 to 60 years old (average: 30 years; SD: 8 years) and their average assignment tenure was 1.9 years $(\mathrm{SD}=2.3)$. Of the group, $11 \%$ work in upper management, $44 \%$ are middle managers, and $45 \%$ are staff members. They work in diverse functional areas, such as finance/accounting (20\%), or marketing/sales (19\%). The demographic information pertaining to the Study 1 participants is summarized in Table 1. 
Insert Table 1 about here

Measures The current research adopts the measure of $S U$ from Brissette et al. (2002) (shorter versions of the scale appear in Carver et al., [1989], and Carver [1997]). The four items measure the degree to which individuals consumed alcohol or drugs to cope with the hardships faced in the past month. A sample question is "I used alcohol or drugs to make myself feel better." The measure was assessed on a 4-point Likert scale anchored with I didn't do this at all (1) and I did this a lot (4). Stress was measured with the 7-item stress subscale of the depression, anxiety, and stress scale (DASS-21; Antony et al., 1998). A sample item is "I found it difficult to relax." Responses were elicited on a 4-point scale anchored with Did not apply to me at all (1) and Applied to me very much, or most of the time (4). Organizational social support was measured using scales from Caplan et al. (1975). This 4-item scale measured the support provided by the supervisor and to the support provided by peers. A sample item is "How much is your supervisor willing to listen to your personal problems?" All items were measured on a 5-point Likert scale anchored with not at all (1) and a great deal (5). Since this work does not focus on peer and supervisor support per se; but on the mitigating role of organizational social support on SU, the numerical responses to the two scale items were summed in order to compute the organizational social support measure. This procedure is in line with previous work focusing on the social support for coping responses (e.g., Fugate et al., 2002) that averaged the perceived support provided by different sources and assessed it with the scale from Caplan et al. (1975). Experience was measured through asking respondents the number of countries they have worked in, including the current host country. Categories were: $1=$ one country, $2=$ two 
countries, $3=$ three countries and $4=$ four or more. The method adopted included controlling for age, type of expatriation (self-initiated or corporate), marital status and family accompaniment (asking whether the expatriates were accompanied by member(s) of their family or their partner). Given its prevalence, French nationality was also controlled for.

\section{Study 2: Consequences of SU}

To assess the consequences of $\mathrm{SU}$, a second data collection effort was made. International mobility managers or compensation and benefits directors of two organizations agreed to send a questionnaire to their expatriate staff and another questionnaire was sent to their supervisors. These professionals belonged to the authors' professional networks and were not incentivized monetarily. These organizations were European multinational companies in the electronics and luxury industries employing tens of thousands of employees. A total of 306 expatriates received the electronic questionnaire and 154 completed it and sent it back directly to the researcher (response rate 50\%). Complete questionnaires were received by researchers from 96 of their supervisors with their assessment of the expatriates' adjustment. The respondents work in 20 countries: the most commonly represented were Singapore (36\%), the USA (15\%), and China (11\%). The majority were French citizens (47\%), but the whole sample represented 12 different countries. Of the respondents, $20 \%$ were female and $9 \%$ were self-initiated expatriates. The average age was 40 ( $\mathrm{SD}=8$ years). The respondents mainly held upper management $(24 \%)$, middle management $(52 \%)$ and lower management $(24 \%)$ positions. The demographic information pertaining to the participants in Study 2 is summarized in Table 2.

Insert Table 2 about here 
Measures. Professional adjustment was measured using the Black and Stephens (1989) scale. A sample item is "How adjusted is $\mathrm{X}$ to his/her job responsibilities?" $S U$ was measured as indicated in Study 1. Length of stay in the host country was also controlled for.

\section{Ethical considerations}

The respondents were assured their answers were confidential, and that only the academic researchers would have access to them. Companies received only an aggregated analysis averaging the answers of at least 30 respondents. Moreover, participation was voluntary, and respondents were informed that they should ignore any questions they felt uncomfortable answering. Finally, each item measuring SU associates alcohol and drugs in the same sentence, and therefore the answers cannot provide any information on illegal behavior of respondents.

\section{Results}

Among the 359 expatriates that reported their SU, 14\% reported consuming some alcohol or drugs to help them address hardship. In the subsample for whom stress was measured (208 expatriates), 55\% reported sometimes stressed, while $8 \%$ reported being considerably stressed. Multiple hierarchical regressions were used to test curvilinear relationships (Le et al., 2011). The independent variables were standardized to avoid multicollinearity (Aiken and West, 1991).

\section{Common method bias check, confirmatory factor analysis and multicollinearity check}

Because this study is based on cross-sectional data collection, it incorporates some measures to limit common method variance (CMV) ex ante. Additional tests were run in order to assess the reliability of the measures too. The questionnaire and procedures were designed to limit self- 
presentation and CMV biases (Chang et al., 2010; Podsakoff et al., 2003). First, respondents were assured of the confidentiality of the study and asked to answer as honestly as possible. It was also clearly stated that there were no correct or incorrect answers (Chang et al., 2010). Second, respondents were asked to send the completed questionnaire directly to a researcher whom they did not know at all, without copying the acquaintance or colleague that solicited them. Moreover, the four items measuring the key construct of this work (SU) were mixed within the questionnaires. Two of the three moderator independent variables (gender and experience) are facts, and consequently less subject to CMV (Chang, Witteloostuijn, and Eden, 2010). These procedures considerably reduce the risk of social desirability bias. Next, all the antecedents in regressions were standardized to limit the threat of multicollinearity (Aiken and West, 1991).

From a post hoc analytical perspective, a confirmatory factor analysis was run on the three latent factors with multiple scales items (stress, organizational support, and SU). The model fits the data well $\left(\chi^{2}=272,6, d f=143, p<.01 ; \mathrm{CFI}=.93 ; \mathrm{RMSEA}=.07\right)$. In order to assess potential CMV, the first unrotated factor was extracted, which should account for less than $50 \%$ of the variance to indicate that CMV is low (Harman's single factor test). It accounted for only $19.8 \%$ of the variance. Moreover, concerns over multicollinearity were addressed by the bi-variate correlations between all variables (Tables 3 and 5) not exceeding 0.30, except in the case of relationship status and family accompaniment (0.58). Finally, the variance inflated factors were computed and were all below 2.0, which indicates that multicollinearity is not an issue in our analyses (Hair et al., 2006).

SU determinants - Study 1

Means, standard deviation, and Cronbach's alphas are presented in Table 3 and multiple regressions in Table 4. In Model 1, the control variables were entered. In Model 2, the linear effect of stress was added, which proved to be significantly and positively related with SU ( $\beta$ 
$=.23 ; p<.001)$. The overall model was significant $\left(\mathrm{R}^{2}=.05\right)$ and showed a significant change in $\mathrm{R}^{2}$ from Model 1. To test our hypotheses that involve curvilinearity, a quadratic term (i.e., squared) was included. In Model 3, the quadratic term of stress was included to test for a curvilinear relationship. Results show that the quadratic term was significantly and positively related to $\mathrm{SU}(\beta=.18 ; p<.05)$. Figure 2 shows that there is a curvilinear relationship between stress and SU. The degree of stress does not strongly affect SU when it is low. However, when the stress level is between the medium and high levels, it strongly impacts upon and increases SU. Therefore Hypothesis 1 is supported.

In Model 4, the moderator variables were added, and in Models 5-7 the interactions between the proposed moderators and the non-squared and squared terms for SU were added. In Model 5, the interaction term representing the interaction between stress and organizational social support was included, as well as the interaction between the quadratic term of stress and organizational social support. No support for either the linear $(\beta=.01 ; p>.05)$ or the quadratic $(\beta=.12 ; p>.05)$ interaction terms was found. Thus Hypothesis 2 is not supported. In Model 6, the interaction terms representing the interaction between stress and experience, as well as that between the quadratic term of stress and experience, were included. Results show that both interaction terms are significant (linear: $\beta=.31 ; p<.001$ and quadratic: $\beta=.17 ; p<.05$ ) and the change in $\mathrm{R}^{2}$ from Model 4 is significant. The interaction is plotted in Figure 3. According to Figure 3, stress triggers greater SU among experienced expatriates. Experience significantly moderated the stress-SU relationship, but contrary to our hypothesis, it has a positive effect. Stress among individuals who have already been in the expatriate scenario several times is more likely to trigger SU than it is for the first-time expatriates. Hypothesis 3 is therefore not supported. 
Insert Tables 3 and 4 and Figures 2, 3 and 4 about here

Finally, Model 7 added the interaction terms representing the interaction between stress and gender as well as between the quadratic term of stress and gender. Results show that the quadratic interaction term is significant $(\beta=-.22 ; p<.01)$ and the change in $\mathrm{R}^{2}$ from Model 4 is significant. To interpret the results, the interaction was plotted. Figure 4 shows that stress does not really impact SU among women: female expatriates consume low levels of substances regardless of their level of stress. Male expatriates consume more drugs or alcohol when they experience higher stress levels. These results provide support for Hypothesis 4.

SU outcomes - Study 2

Means, standard deviation, and Cronbach's alphas are shown in Table 5 and multiple regressions are presented in Table 6. Model 1 incorporates the control variable (length of stay). Model 2 adds the linear effect of SU. The results show that SU was significantly and negatively related to professional adjustment $(\beta=.-23 ; p<.05)$. The overall model showed a significant change in $\mathrm{R}^{2}$ from Model 1 . Thus, Hypothesis 5 is supported.

Insert Tables 5 and 6 about here

\section{Discussion}


First, this work helps explain why expatriates consume more alcohol and drugs than domestic employees (Truman et al., 2011). By outlining the potential influence of stress in that consumption, this work offers some support to the application of the tension reduction theory in expatriation (Conger, 1956; Cooper, 1994). Stress does have an effect on SU during expatriation: expatriates experiencing stress at either the medium or high levels use more substances. However, in line with domestic findings, this relationship holds more strongly for men and the tension reduction theory seems to be less effective when predicting SU among women. Moreover, it appears that the stress-SU relationship is curvilinear: at a low level, stress does not lead to an increase in SU but to a decrease. This research consequently also provides interesting findings for the consequence of stress. It shows that in some cases it can have curvilinear influences (Takeuchi et al., 2007), and that, at least in the expatriation scenario, having too low a stress level can be detrimental to some extent.

Second, the current research studied factors that have a detrimental or a protective effect on stress-induced SU. Our study indicates that there was significant variation in the relationship that could be predicted by gender and experience. No relationship between stress and SU was found in the case of female expatriates. Women are not reacting to stress abroad by drinking or taking drugs. This finding accords with research in the domestic context (e.g., Cooper et al., 1992): it appears that often men react to stressors by taking substances while women do not (e.g., Belogolovsky et al., 2012). Socialization processes might explain this phenomenon because women seem to be more socialized to internalize stress, while men are more socialized to express distress, and for instance to use alcohol (Cooper et al., 1992; Dohrenwend and Dohrenwend, 1976; Horwitz and White, 1987). This finding complements gender research on expatriation, in that it extends prior findings that there may be gender differences in how expatriates cope and adjust (Tung, 2004).

Third, running counter to our hypothesis, experience as an expatriate worker moderates 
the stress-SU relationship but positively; more experienced expatriates consume more substances when they are stressed. This result echoes the mixed results of investigations of the role of experience in the form of previous expatriations on outcomes such as adjustment (Bhaskar-Shrinivas et al., 2005; Hechanova et al., 2003; Takeuchi and Chen, 2013), and also of recent research that suggests international experience may also have negative outcomes ( $\mathrm{Lu}$ et al., 2017). Takeuchi and Chen (2013) theorize that the negative impact of experience might be explained by experienced expatriates bypassing the phase of being charmed by their new surroundings and culture and instead immediately experiencing the more negative aspects of culture shock.

No evidence for organizational social support offering a buffer between stress and SU has been found. This echoes the finding of Takeuchi et al. (2009:623) that described perceived organization support as, "mixed and equivocal." The shortcomings in organizational social support can be explained by the specificity hypothesis (Cohen and Wills, 1985; Peirce et al., 1996) that suggests social support has an effective buffering effect only if it is relevant to the source of stress. The stress experienced by expatriate staff is unlikely to be solely generated by work but will also be created by the non-working environment and issues like maladjustment. For instance, isolation probably affects expatriates more outside of work than in the workplace. Hence, there may be more sources of stress outside work than within it. Social support received outside of work may therefore have more of an impact than workplace support. SU may nonetheless still be explained by the lack of support mechanisms - the failure of expatriates to develop their own forms of support and the limited support available in some host locations.

Finally, the impaired functioning theory and findings from domestic settings (Newcomb and Bentler, 1988) apply to expatriation too: the current study provides evidence that SU while abroad affects professional outcomes. Professional adjustment-adjustment to work responsibilities — as evaluated by supervisors and colleagues, is harmed by SU. This finding 
extends the body of literature on expatriate adjustment and its antecedents (e.g., Shaffer et al., 1999): SU is a source of maladjustment at work. As it has been showed in general literature (e.g., Bacharach et al., 2010), this result suggests that SU while abroad may affect other important work-related outcomes, such as absenteeism and also health and family-related outcomes. Moreover, professional maladjustment may increase stress levels and the stress-SUmaladjustment cycle could become self-reinforcing.

\section{Practical implications}

This work develops our understanding of expatriate SU. This issue should be addressed by human resources (HR) managers and should be prioritized because SU could have lifethreatening consequences for employees working in dangerous environments such as factories, mines, or oil rigs. Local HR managers in charge of expatriates should be made aware of these potential issues. They could organize policies and support initiatives that would help limit SU. Such action might involve offering anonymous support groups ${ }^{2}$ and organizing testing in dangerous work environments. Candidates for corporate expatriate positions should be informed of the increased risks of SU while abroad before they accept an international assignment.

The findings of the current research suggest several additional paths. The role of stress in SU indicates firms should back the implementation of programs designed to reduce stress that are also likely to decrease SU. Such programs might include stress-relief techniques (such as meditation or yoga), attempts to limit work demands and conflict experienced by expatriates, and cross-cultural training or coaching to ease cultural adjustment and raise awareness of the potential issues of SU while abroad. Moreover, this research helps to identify some populations,

\footnotetext{
${ }^{2}$ We thank an anonymous reviewer for this suggestion.
} 
namely experienced and male expatriates, at risk of substance abuse. Local HR managers could take particular care of these populations and consider how they might provide the relevant support or information to prevent people at risk from being drawn into the vicious cycle of substance abuse. Finally, some host locations are more stressful. For instance, safety issues, related either to terrorism and crime are acutely stressful for expatriates (Bader and Berg, 2013; Faeth and Kittler, 2017). Employees facing such heightened stressors may be more at risk of SU. Relevant support to the expatriate in countries affected by such issues should be organized.

\section{Limitations and future research}

The research has some straightforward limitations. First, SU was self-reported and the amount of SU reported in the sample is low. Some users may well have declined to reveal the full extent of their SU in our questionnaire. Although the respondents sent the questionnaire directly to the researcher, they might have been concerned that some of their company managers would see their answers. The proportion of expatriates taking drugs is likely to be higher than is reported here. Future research on expatriate SU could involve management researchers and medical doctors, and include other data sources, such as partners of the expatriates, in order to increase the reliability of the measures of SU.

Second, because the data used to investigate SU antecedents were self-reported and collected from expatriates, common method bias might have affected our analyses. Common method bias inflates the main effects and prevents the detection of interactions (Evans, 1985). Nonetheless, significant interaction effects were observed. Moreover, the cross-sectional design of Study 1 limits causal interpretations. Third, this work is based on convenience samples of limited size. Additionally, the samples of the two studies are very different in terms of age, gender, and type of expatriate. Study 1 involves a young sample, mainly self-initiated 
expatriates and is quite balanced in terms of gender, while Study 2 is based on a more classic corporate expatriate sample, one that is older and very masculine. These important differences raise questions regarding the compatibility of the samples and the generalizability of the findings. Larger and more representative samples should provide more robust findings and help identify boundary conditions of the use of alcohol and drugs. Specific situations, such as the host country and specific populations (as found for female and male examples) are likely to affect alcohol and drugs consumption abroad.

This research provides additional evidence that tension reduction theory may not explain women's alcohol consumption (e.g., Kalodner et al., 1989). It has been shown that even for men, SU may not be directly caused by stressors, but mediated by other stress-induced reactions (such as lack of sleep; Belogolovsky et al., 2012). One alternative hypothesis to tension reduction theory is that stressors affect individuals' resources, which in turn influence SU in line with the resource ecology perspective (Hobfoll, 1988). Another alternative approach suggests that expectations of the effects of alcohol can play an important role (Young et al., 1990). This calls for additional studies to assess other determinants of SU, such as previous habits and expectations related to the effect of consuming substances. The role of specific stressors should also be investigated: expatriates face various stressors, some are more prone to trigger SU than others, for example, constraints on freedom of choice (to expatriate), cultural novelty, role conflict, or safety issues (Kraimer and Wayne, 2004; Bader and Berg, 2013; Faeth and Kittler, 2017).

Future research might also usefully examine the impact of social norms in connection with SU. Social norms have been shown to affect SU in domestic situations (e.g., Wang et al., 2010). The tolerance of alcohol and drug use within the host country, the host organization, and in the expatriate community could affect SU among individual expatriate staff. Alcohol consumption can even be part of the local business culture and be used in specific circumstances 
to ease professional adjustment (e.g., Kim and Kim, 2008). Another research direction might involve identifying the substance used, and the way it is consumed. The type of substance (alcohol or drugs; type of drug), the frequency of consumption, and the quantity consumed in a session are likely to affect the outcomes of the use (e.g., Frone, 2004). Moreover, the social dimension of the intake should also be taken into account: research might investigate if the individual engages in this behavior alone, with family members, with colleagues, with business partners, with other expatriates, or with host-country nationals? Finally, more qualitative research on expatriate SU would be very useful. Such research could provide more information on when, how, and why expatriates resort to SU.

\section{Conclusion}

Living and working abroad brings many challenges, which cause expatriates to have higher levels of stress and to consume more alcohol and tobacco than domestic employees would. This work contributes to unveiling well-being issues in expatriation. It illustrates several at-risk sub-populations and provides evidence of detrimental work consequences associated with the use of substances. Further research on the topic might help HR managers provide expatriates with adequate support to enhance expatriate well-being. 


\section{References}

Aiken, L.S. and West, S.G. (1991), Multiple regression: Testing and interpreting interactions, Sage, Newbury Park, CA.

Amiot, C. E., Terry, D. J., Jimmieson, N. L. and Callan, V. J. (2006), “A longitudinal investigation of coping processes during a merger: Implications for job satisfaction and organizational identification”, Journal of Management, 32(4), 552-574.

Anderzén, I. and Arnetz, B.B. (1997), "Psychophysiological reactions during the first year of a foreign assignment: Results of a controlled longitudinal study", Work and Stress, Vol. 11, pp. 304-318.

Anderzén, I. and Arnetz, B.B. (1999), "Psychophysiological Reactions to International Adjustment: Results from a Controlled, Longitudinal Study", Psychotherapy and Psychosomatics, Vol. 68 No. 2, pp. 67-75.

Anderson, C.R., (1976), "Coping behaviors as intervening mechanisms in the inverted-U stressperformance relationship", Journal of Applied Psychology, Vol. 61 No. 1, p. 30.

Antony, M., Bieling, P J., Cox, B. J., Enns, M.W. and Swinson, R.P. (1998), "Psychometric properties of the 42-item and 21-item versions of the Depression Anxiety Stress Scales in clinical groups and a community sample", Psychological Assessment, Vol. 10, pp.176-181.

Bacharach, S. B., Bamberger, P. and Biron. M. (2010), "Alcohol consumption and workplace absenteeism: The moderating effect of social support", Journal of Applied Psychology, Vol. 95, No. 2, p. 334.

Bader, B. and Berg, N. (2013), "An empirical investigation of terrorism-induced stress on expatriate attitudes and performance", Journal of International Management Vol.19 No. 2, pp. 163-175.

Belogolovsky, E., Bamberger, P. A. and Bacharach, S. B. (2012),” Workforce disengagement stressors and retiree alcohol misuse: The mediating effects of sleep problems and the moderating effects of gender", Human Relations, Vol. 65 No. 6, pp. 705-728.

Berry, J. W. and Kalin, R. (1995), "Multicultural and ethnic attitudes in Canada: An overview of the 1991 national survey", Canadian Journal of Behavioural Science/Revue canadienne des sciences du comportement, Vol.27, no. 3, p.301.

Bhaskar-Shrinivas, P., Harrison, D.A., Shaffer, M.A. and Luk, D.M. (2005), "Input-based and 
time-based models of international adjustment: Meta-analytic evidence and theoretical extensions", Academy of Management Journal, Vol. 48 No. 2, pp. 257-281.

Black, J. S., Mendenhall, M. and Oddou, G. (1991), "Toward a comprehensive model of international adjustment: An integration of multiple theoretical perspectives", Academy of Management Review, Vol. 16 No.2, pp. 291-317.

Black, J. S. and Stephens, G. K. (1989), "The influence of the spouse on American expatriate adjustment and intent to stay in Pacific Rim overseas assignments", Journal of management Vol. 15, No. 4, pp. 529-544.

Brissette, I., Scheier, M.F. and Carver, C.S. (2002), "The role of optimism in social network development, coping, and psychological adjustment during a life transition”, Journal of Personality and Social Psychology, Vol. 82 No. 1, pp.102-111.

Caligiuri, P. M. (2000), “Selecting expatriates for personality characteristics: A moderating effect of personality on the relationship between host national contact and cross-cultural adjustment”, MIR: Management International Review,pp. 61-80.

Caplan, R.D., Cobb, S., French, J.R.P., Harrison, R. and Pinneau, S.R. (1975), Job demands and worker health (National Institute for Occupational Safety and Health Publication No. 75160). Department of Health, Education, and Welfare, Washington, DC.

Carver, C. S. (1997) "You want to measure coping but your protocol's too long: Consider the brief cope", International journal of behavioral medicine Vol.4 No. 1, p. 92.

Carver, C. S., Scheier, M. F. and Weintraub, J. K. (1989), “Assessing coping strategies: a theoretically based approach", Journal of personality and social psychology, Vol. 56 No. 2, p. 267.

Chang, S.J., Van Witteloostuijn, A. and Eden, L. (2010), "From the editors: common method variance in international business research", Journal of International Business Studies, Vol. 41 No. 2, pp. 178-184.

Cohen, S. and Wills, T.A. (1985), "Stress, social support, and the buffering hypothesis", Psychological Bulletin, Vol. 98, pp. 310-357.

Conger J.J. (1956), “Alcoholism: Theory, problem and challenge. II. Reinforcement theory and the dynamics of alcoholism", Journal of Studies on Alcohol, Vol. 13, pp. 296-305.

Cooper, M. L. (1994), "Motivations for alcohol use among adolescents: Development and 
validation of a four-factor model", Psychological assessment Vol.6, no. 2, p.117.

Cooper, M. L., Russell, M. and Frone, M. R. (1990), "Work stress and alcohol effects: A test of stress-induced drinking", Journal of Health and Social Behavior, 260-276.

Cooper, M. L., Russell, M. and George, W. H. (1988), “Coping, expectancies, and alcohol abuse: A test of social learning formulations", Journal of abnormal psychology, 97(2), 218.

Cooper, M.L., Russell, M., Skinner, J.B., Frone, M.R. and Mudar, P. (1992), "Stress and alcohol use: Moderating effects of gender, coping, and alcohol expectancies", Journal of Abnormal Psychology, Vol. 101, pp. 139-152.

Dawson D.A, Grant B.F. and Ruan W.J. (2005), "The association between stress and drinking:Modifying effects of gender and vulnerability", Alcohol and Alcoholism, Vol. 40, pp. 453-460.

Doherty, N., Dickmann, M. and Mills, T. (2011), "Exploring the Motives of Company-Backed and Self-Initiated Expatriates", International Journal of Human Resource Management, Vol. 22 No. 3, pp. 595-611.

Dohrenwend, B.P. and Dohrenwend, B.S., (1976), "Sex differences and psychiatric disorders", American journal of sociology, 81(6), pp.1447-1454.

Evans, M.G. (1985), “A Monte Carlo study of the effects of correlated method variance in moderated multiple regression analysis", Organizational Behavior and Human Decision Processes, Vol.36, pp. 305-323.

Faeth, P. C. and Kittler. M. G. (2017), "How do you fear? Examining expatriates' perception of danger and its consequences", Journal of Global Mobility: The Home of Expatriate Management Research, Vol. 5, No. 4, pp. 391-417.

Fontaine, G. (1989), “Managing international assignments: The strategy for success”, Prentice Hall Direct.

Frone M. R. (2004), “Alcohol, drugs, and workplace safety outcomes: A view from a general model of employee substance use and productivity", in Barling J, Frone MR (Eds.), The psychology of workplace safety, American Psychological Association, Washington, DC, pp. $127-156$.

Frone, M. R., Russell, M. and Cooper, M. L. (1995), “Job stressors, job involvement and employee health: A test of identity theory", Journal of Occupational and Organizational 
Psychology, Vol. 68, No.1, pp.1-11.

Fugate, M., Kinicki, A. J. and Scheck, C. L. (2002), “Coping with an organizational merger over four stages”, Personnel Psychology, Vol.55, No.4, pp. 905-928

Galaif, E. R., Newcomb, M. D. and Carmona, J. V. (2001), "Prospective Relationship Between Drug Problems and Work Adjustment in a Community Sample of Adults", Journal of Applied Psychology, Vol. 86 No. 2, pp. 337-350.

Gibbons, F. X., Etcheverry, P. E., Stock, M. L., Gerrard, M., Weng, C., Kiviniemi, M. T. and O'Hara, R. E. (2010), “Exploring the link between racial discrimination and substance use: What mediates, what buffers?" Journal of Personality and Social Psychology, Vol. 99, pp. 785801.

Hair, J.E., Babin, W.C., Babin., B.J., Anderson, R.E. and Tatham, R.L. (2006), Multivariate Data Analysis, 6th ed., Prentice Hall, Englewood Cliffs, NJ.

Harvey, M. and Moeller, M. (2009), "Expatriate mangers: A historical review”, International Journal of management reviews, 11(3), 275-296.

Haslberger, A., Brewster, C. and Hippler, T. (2014), Managing Performance Abroad: a new model for understanding expatriate adjustment, Routledge, London

Haslberger, A. Hippler, T. and Brewster, C. (forthcoming), “Adjustment of Expatriate Families", In McNulty, Y. (Ed). Research Handbook of Global Families: Implications for International Business, Edward Elgar, Cheltenham.

Hechanova, R., Beehr, T. A. and Christiansen, N. D. (2003), “Antecedents and consequences of employees' adjustment to overseas assignment: A meta analytic review", Applied Psychology: An International Review, Vol. 52, pp. 213-236.

Hobfoll, S. E. (1988) The ecology of stress, Taylor and Francis.

Horwitz, A.V. and White, H.R. (1987), “Gender role orientations and styles of pathology among adolescents", Journal of Health and Social Behavior, Vol. 28, pp. 158-170.

Hull, J. G. (1981), “A self-awareness model of the causes and effects of alcohol consumption", Journal of Abnormal Psychology, Vol. 90 No. 6, p.586. 
Jokinen, T., Brewster, C. and Suutari, V. (2008), "Career capital during international work experiences: contrasting self-initiated expatriate experiences and assigned expatriation", International Journal of Human Resource Management, Vol. 19 No. 6, pp. 981-1000.

Kalodner, C. R., Delucia, J. L. and Ursprung, A. W. (1989), “An examination of the tension reduction hypothesis: the relationship between anxiety and alcohol in college students", Addictive behaviors, Vol. 14 No. 6, 649-654.

Kaplan, H. B. and Demphouse, K. R. (1995), "Self-attitudes and antisocial personality as moderators of the drug use-violence relationship", in H.B. Kaplan (Ed.), Drugs, crime, and other deviant adaptations: Longitudinal studies, Plenum Press, New York, pp. 187-210.

Kim, W. and Kim, S. (2008), "Women's alcohol use and alcoholism in Korea", Substance use and misuse, Vol. 43, No. 8-9, pp. 1078-1087.

Kraimer, M. L. and Wayne, S. J. (2004), "An examination of perceived organizational support as a multidimensional construct in the context of an expatriate assignment", Journal of Management, Vol.30, No. 2, pp. 209-237.

Lui, S., Wang, M., Zhan, Y. and Shi, J., (2009), "Daily work stress and alcohol use: testing the cross-level moderation effects of neuroticism and job involvement", Personnel Psychology, Vol. 62, pp. 575-597.

Le, T., Oh, I.S., Robbins, S. B., Illies, R., Holland, E. and Westrick, P. (2011), "Too much of a good thing: Curvilinear relationships between personality traits and job performance", Journal of Applied Psychology, Vol. 96 No. 1, pp. 112-133.

Lu, J. G., Quoidbach, J., Gino, F., Chakroff, A., Maddux, W. W. and Galinsky, A. D. (2017). The dark side of going abroad: How broad foreign experiences increase immoral behavior. Journal of personality and social psychology, Vol. 112 No.1, p.1.

Liu, S., Wang, M., Zhan, Y. and Shi, J. (2009), "Daily work stress and alcohol use: Testing the cross-level moderation effects of neuroticism and job involvement", Personnel Psychology Vol.62, No. 3, pp. 575-597.

Mäkelä, L. and Suutari, V. (2011), “Coping with work-family conflicts in the global career context”, Thunderbird International Business Review, 53(3), pp. 365-375.

Mangione, T.W., Howland, J., Amick, B., Cote, J., Lee, M., Bell, N. and Levine, S. (1999), "Employee drinking practices and work performance", Journal of studies on alcohol, Vol. 60 
No. 2, pp. 261-270.

McFarlin, S. K. and Fals-Stewart, W. (2002), "Workplace absenteeism and alcohol use: A sequential analysis", Psychology of Addictive Behaviors, Vol. 16, pp. 17-21.

McNulty, Y. (2015), “Till stress do us part: The causes and consequences of expatriate divorce”, Journal of Global Mobility, 3(2), 106-136.

Newcomb, M. D. (1988), Drug Use in the Workplace: Risk Factors for Disruptive Substance Use Among Young Adults. Auburn House, Dover, MA.

Newcomb, M. D. and Bentler, P. M. (1988), Consequences of adolescent drug use: Impact on the lives of young adults, Sage Publications, Inc.

Nordlicht, S. (1979), "Effects of stress on the police officer and family", New York State Journal of Medicine, 79, 400-401.

Pascoe, R. and Moser, C. (2009). "Substance Abuse in Expatriate Life. Living Overseas." Available at: http://www.escapefromamerica.com/2009/03/abuse-in-expatriate-life/

Peirce, R. S. Frone, M. R., Russell, M. and Cooper, M. L. (1996), "Financial stress, social support, and alcohol involvement: A longitudinal test of the buffering hypothesis in a general population survey", Health Psychology, Vol. 15, pp. 38-47.

Podsakoff, P. M., MacKenzie, S. B., Lee, J. Y. and Podsakoff, N. P. (2003), “Common method biases in behavioral research: A critical review of the literature and recommended remedies", Journal of Applied Psychology, Vol. 88, pp.879-903.

Rohsenow, D. J. (1983), "Drinking habits and expectancies about alcohol's effects for self versus others", Journal of consulting and clinical psychology, Vol. 51 No. 5, p.752.

Shaffer, M. A., Harrison, D. A. and Gilley, K. M. (1999). Dimensions, determinants, and differences in the expatriate adjustment process. Journal of International Business Studies, $30(3), 557-581$.

Shaffer, M., Singh, B. and Chen, Y.-P. (2013), "Expatriate pay satisfaction: the role of organizational inequities, assignment stressors and perceived assignment value", The International Journal of Human Resource Management, Vol.24, no. 15, pp. 2968-2984.

Steele, C. M. and Josephs, R. A. (1988), "Drinking your troubles away II: An attentionallocation model of alcohol's effect on psychological stress", Journal of abnormal psychology, Vol. 97 No. 2, pp. 196-205. 
Suutari, V., Wurtz, O. and Tornikoski, C. (2014), "How to attract and retain global careerists: Evidence from Finland”, In Global talent management (pp. 237-249), Springer, Cham.

Takeuchi, R. and Chen, J. (2013), “The impact of international experiences for expatriates' cross-cultural adjustment: A theoretical review and a critique", Organizational Psychology Review, Vol. 3 No.3, pp.248-290.

Takeuchi, R., Lepak, D. P., Marinova, S. V. and Yun, S. (2007), "Nonlinear influences of stressors on general adjustment: The case of Japanese expatriates and their spouses", Journal of International Business Studies, Vol. 38 No. 6, pp.928-943.

Takeuchi, R., Wang, M. and Marinova, S. V. (2005), “Antecedents and consequences of psychological workplace strain during expatriation: A cross-sectional and longitudinal investigation", Personnel Psychology, Vol. 58 No. 4, pp.925-948.

Takeuchi, R., Wang, M., Marinova, S. V. and Yao, X. (2009), "Role of Domain-Specific Facets of Perceived Organizational Support During Expatriation and Implications for Performance", Organization Science, Vol. 20 No. 3, pp. 621-634.

Truman, S. D., Sharar, D. A. and Pompe, J. C. (2011), “The mental health status of expatriate versus U.S. domestic workers: A comparative study", International Journal of Mental Health, Vol. 40 No. 4, pp. 3-18.

Tung, R. L. (1987), “Expatriate assignments: Enhancing success and minimizing failure”, The Academy of Management Executive (1987-1989), pp. 117-125.

Tung, R. L. (1988), "American expatriates abroad: From neophytes to cosmopolitans", Journal of world business Vol.33, No. 2, pp. 125-144.

Tung, R. L. (2004), “Female Expatriates: The Model Global Manager?” Organizational Dynamics, Vol. 33 No. 3, pp. 243-251.

Van Vianen, A. E., De Pater, I. E., Kristof-Brown, A. L. and Johnson, E. C. (2004), "Fitting in: Surface-and deep-level cultural differences and expatriates' adjustment”, Academy of Management Journal, 47(5), 697-709.

Wang, M., Liu, S., Zhan, Y. and Shi, J. (2010), "Daily Work-Family Conflict and Alcohol Use: Testing the Cross-Level Moderation Effects of Peer Drinking Norms and Social Support", Journal of Applied Psychology, Vol. 95 No. 2, pp. 377-386.

Wills, T. A. and Cleary, S. D. (1996), "How are social support effects mediated: A test for 
parental support and adolescent substance use", Journal of Personality and Social Psychology, Vol. 71, pp. 937-952.

Yavas, U. and Bodur, M. (1999). Correlates of adjustment: a study of expatriate managers in an emerging country. Management Decision, Vol. 37 No. 3, 267-279.

Yerkes, R. M. and Dodson, J. D. (1908), "The relation of strength of stimulus to rapidity of habit-formation", Journal of comparative neurology, Vol. 18 No. 5, pp. 459-482.

Young, R., Oei T. P. S. and Knight, R. G. (1990), "The tension reduction hypothesis revisited: An alcohol expectancy perspective", Addiction Vol.85, No. 1, pp. 31-40.

Zhu, J., Wanberg, C. R., Harrison, D. A. and Diehn, E. W. (2016), "Ups and downs of the expatriate experience?", Understanding work adjustment trajectories and career outcomes. Journal of Applied Psychology, Vol. 101 No. 4, p.549. 
FIGURE 1.

Presentation of the hypotheses

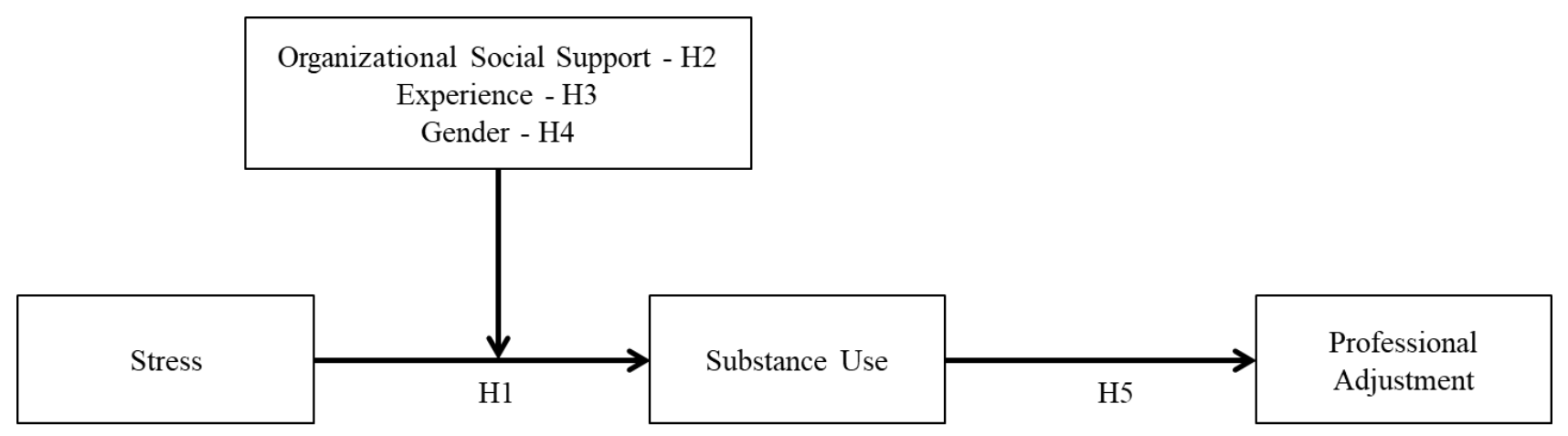


Table 1

Demographic Profiles of Study 1

\begin{tabular}{lc}
\hline Demographic Variable & \% of Sample \\
\hline Gender & 42 \\
Female & 58 \\
Male & \\
& \\
Age & 11 \\
$<25$ & 50 \\
$25-29$ & 31 \\
$30-39$ & 6 \\
$40-49$ & 2 \\
$50+$ & \\
& \\
Expatriation nature & 70 \\
Self-initiated & 30 \\
Organizational & \\
Position Level & 11 \\
Upper management & 44 \\
Middle management & 45 \\
Staff & \\
Marital status & \\
Married/in a relationship & 64 \\
Single & 36 \\
Family accompaniment & \\
Accompanied by members of family & 42 \\
Not accompanied & 58 \\
\hline
\end{tabular}


Table 2

Demographic Profiles of Study 2

\begin{tabular}{lc}
\hline Demographic Variable & \% of Sample \\
\hline Gender & 20 \\
Female & 80 \\
Male & \\
& \\
Age & 3 \\
$<25$ & 7 \\
$25-29$ & 43 \\
$30-39$ & 39 \\
$40-49$ & 8 \\
$50+$ & \\
& \\
Expatriation nature & 91 \\
Self-initiated & 9 \\
Organizational & \\
& \\
Position Level & 24 \\
Upper management & 52 \\
Middle management & 24 \\
Staff & \\
Marital status & \\
Married/in a relationship & 84 \\
Single & 16 \\
Family accompaniment & \\
Accompanied by members of family & 70 \\
Not accompanied & 30 \\
\hline
\end{tabular}


TABLE 3.

Means, Standard Deviation, Internal Consistency Reliabilities, and Pearson Correlations (SU

Antecedents) ${ }^{\text {a }}$

\begin{tabular}{|c|c|c|c|c|c|c|c|c|c|c|c|c|c|}
\hline & Variable & $\mathbf{M}$ & SD & 1 & 2 & 3 & 4 & 5 & 6 & 7 & 8 & 9 & 10 \\
\hline 1. & $\mathrm{SU}^{\mathrm{b}}$ & 1.19 & 0.47 & $(.95)$ & & & & & & & & & \\
\hline 2. & Stress & 2.04 & 0.63 &, $23 * * *$ & $(.85)$ & & & & & & & & \\
\hline 3. & Organizational Social Support & 4.14 & 1.09 & ,09 &, 12 & $(.83)$ & & & & & & & \\
\hline 4. & Experience & 2.47 & 0.92 &, 13 &,- 12 &, 11 & - & & & & & & \\
\hline 5. & Gender $^{\mathrm{c}}$ & 0.43 & 0.50 &,- 04 &, 14 &,- 04 &,- 03 & - & & & & & \\
\hline 6. & Age & 30.13 & 6.57 &,- 12 &,- 06 &,- 09 &, 11 &,$- 17 *$ & - & & & & \\
\hline 7. & Type of expatriation ${ }^{\mathrm{d}}$ & 0.69 & 0.47 &, 02 &, 12 &,- 04 &,$- 14^{*}$ &, $19 * *$ &,- 13 & - & & & \\
\hline 8. & French $^{\mathrm{e}}$ & 0.64 & 0.48 &,- 03 &, 01 &,- 08 &, 09 &,- 12 &,- 13 &,- 06 & - & & \\
\hline 9. & Marital status ${ }^{\mathrm{f}}$ & 1.36 & 0.48 & .08 & .02 & .03 & -.04 & -.08 & $-.22 *$ & $-.15^{*}$ & -.09 & - & \\
\hline 10. & Family accompaniment $\mathrm{g}$ & 1.58 & 0.50 & .03 & .04 & .07 & -.10 & .00 & $-.30 * *$ & -.01 & -.12 & $-.58 * * *$ & - \\
\hline
\end{tabular}

${ }^{\mathrm{a}} \mathrm{N}=205$. Reliability coefficients are in parenthesis on the diagonal.

${ }^{\mathrm{b}}$ Dependent variable

${ }^{\mathrm{C}}$ Gender is coded as 0 -Male, 1 - Female.

${ }^{\mathrm{d}}$ Type of expatriation is coded as 0 - Corporate, 1 - Self-Initiated.

${ }^{\mathrm{e}}$ French is coded 1 , not French 0 .

${ }^{\mathrm{f}}$ Married/in a relationship is coded 1, single 2.

${ }^{\mathrm{g}}$ Accompanied with family (or partner) is coded 1 , not accompanied 2 . 
TABLE 4.

Results of Regression Analysis for $\mathrm{SU}^{\mathrm{a}}$

\begin{tabular}{|c|c|c|c|c|c|c|c|}
\hline \multirow[t]{2}{*}{ Variable } & \multicolumn{7}{|c|}{ SU } \\
\hline & $\begin{array}{c}\text { Model } 1 \\
\beta\end{array}$ & $\begin{array}{c}\text { Model } 2 \\
\beta\end{array}$ & $\begin{array}{c}\text { Model } 3 \\
\beta\end{array}$ & $\begin{array}{c}\text { Model } 4 \\
\beta\end{array}$ & $\begin{array}{c}\text { Model } 5 \\
\beta\end{array}$ & $\begin{array}{c}\text { Model } 6 \\
\beta\end{array}$ & $\begin{array}{c}\text { Model } 7 \\
\beta\end{array}$ \\
\hline \multicolumn{8}{|l|}{ Control } \\
\hline Age & -.12 & -.11 & -.09 & -.12 & -.13 & -.14 & -.11 \\
\hline Type of expatriation ${ }^{b}$ & .00 & -.02 & -.03 & .00 & .01 & -.02 & -.01 \\
\hline French $^{\mathrm{c}}$ & -.05 & -.06 & -.06 & -.08 & -.08 & -.06 & -.07 \\
\hline Marital status ${ }^{\mathrm{d}}$ & .07 & .07 & .07 & .06 & .07 & .03 & .05 \\
\hline Family accompaniment ${ }^{\mathrm{e}}$ & -.05 & -.06 & -.03 & -.03 & -.04 & -.05 & -.01 \\
\hline \multicolumn{8}{|l|}{ Main effects } \\
\hline Stress & & $.23 * * *$ & $.17 *$ & $.20 * *$ & $.19 *$ & $.19 * *$ & $.21 * *$ \\
\hline Stress Squared & & & $.18^{*}$ & $.16^{*}$ & $.15^{*}$ & .14 & $.15^{*}$ \\
\hline \multicolumn{8}{|l|}{ Moderators } \\
\hline Organizational social support & & & & .02 & -.06 & .00 & .02 \\
\hline Experience & & & & $.15^{*}$ & $.14^{*}$ & .03 & .13 \\
\hline Gender $^{\mathrm{f}}$ & & & & -.10 & -.10 & -.07 & .04 \\
\hline \multicolumn{8}{|l|}{ Interaction effects } \\
\hline Stress x Organizational social support & & & & & .01 & & \\
\hline Stress Squared x Organizational social support & & & & & .12 & & \\
\hline Stress x Experience & & & & & & $.31 * * *$ & \\
\hline Stress Squared x Experience & & & & & & $.17 *$ & \\
\hline Stress $x$ Gender & & & & & & & -.04 \\
\hline Stress Squared x Gender & & & & & & & $-.22 *$ \\
\hline $\mathbf{R}^{2}$ & .02 & .07 & .10 & .13 & .14 & .22 & .16 \\
\hline$\Delta \mathbf{R}^{2}$ & & $.05 * * *$ & $.03 *$ & .03 & .01 & $.14 * * *$ & $.03 *$ \\
\hline $\mathbf{F}$ & 0.7 & $2.4^{*}$ & $3.0 * *$ & $2.8 * *$ & $2.5 * *$ & $5.7 * * *$ & $3.0 * * *$ \\
\hline
\end{tabular}

${ }^{\mathrm{a}} \mathrm{N}=205$.

${ }^{\mathrm{b}}$ Type of expatriation is coded as 0 - Corporate, 1 - Self-Initiated.

${ }^{\mathrm{c}}$ French is coded 1, not French 0 .

${ }^{\mathrm{d}}$ Married/in a relationship is coded 1, single 2 .

e Accompanied with family (or partner) is coded 1, not accompanied 2.

${ }^{\mathrm{f}}$ Gender is coded as 0 -Male, 1 - Female. 
TABLE 5.

Means, Standard Deviation, Internal Consistency Reliabilities, and Pearson Correlations (SU

Outcomes) $^{\text {a }}$

\begin{tabular}{|c|c|c|c|c|c|c|c|}
\hline & Variable & M & SD & 1 & 2 & 3 & 4 \\
\hline 1. & Professional Adjustment $^{\mathrm{b}}$ & 5.82 & 1.05 & $(.91)$ & & & \\
\hline 2. & SU & 1.11 & .39 & $-.23^{*}$ & $(.89)$ & & \\
\hline 3. & Length of stay ${ }^{c}$ & 42.76 & 35.73 & .05 & -.08 & - & \\
\hline
\end{tabular}

TABLE 6.

Results of Regression Analysis for Professional Adjustment ${ }^{\text {a }}$

\begin{tabular}{lcc}
\hline & Variable & \multicolumn{2}{c}{$\begin{array}{c}\text { Professional } \\
\text { Adjustment }\end{array}$} \\
\cline { 2 - 3 } & $\begin{array}{c}\text { Model 1 } \\
\beta\end{array}$ & $\begin{array}{c}\text { Model 2 } \\
\beta\end{array}$ \\
\hline $\begin{array}{l}\text { Control } \\
\text { Length of stay }\end{array}$ & .05 & .03 \\
$\quad$ Main effects & & \\
$\quad \mathrm{SU}$ & & $-.23^{*}$ \\
$\mathbf{R}^{2}$ & .00 & .06 \\
$\Delta \mathbf{R}^{2}$ & 0.2 & $.06^{*}$ \\
$\mathbf{F}{ }^{\mathrm{a}} \mathrm{N}=96$. & & \\
${ }^{\mathrm{b}}$ Length of stay in the host country in months. & &
\end{tabular}


FIGURE 2.

Curvilinear Relationship between Stress and SU

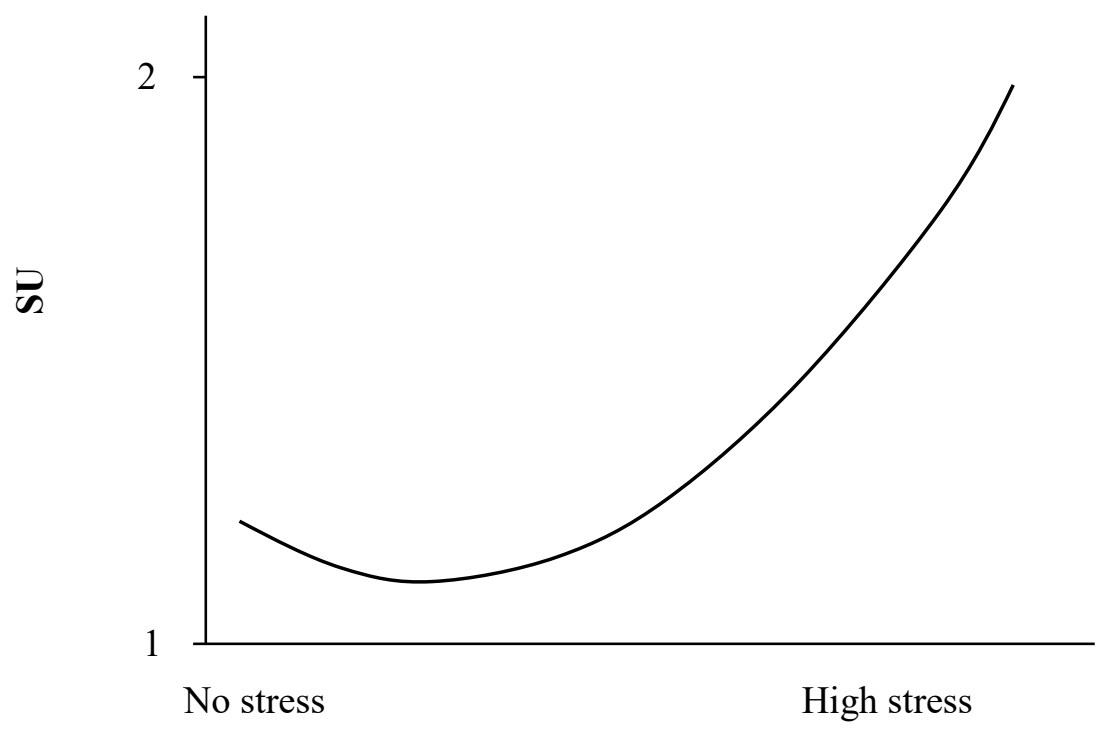

FIGURE 3.

Moderating Effect of Experience on the Relationship between Stress and SU

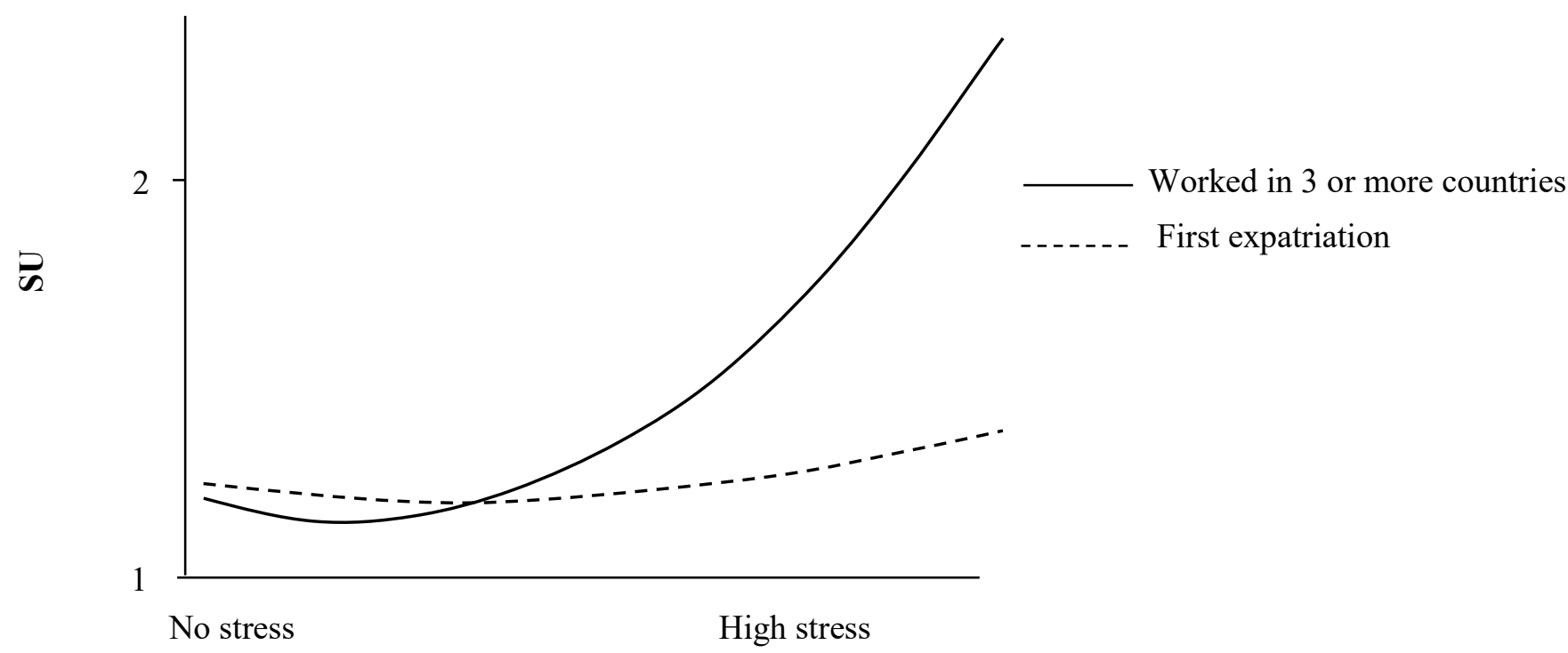


FIGURE 4.

Moderating Effect of Gender on the Relationship between Stress and SU

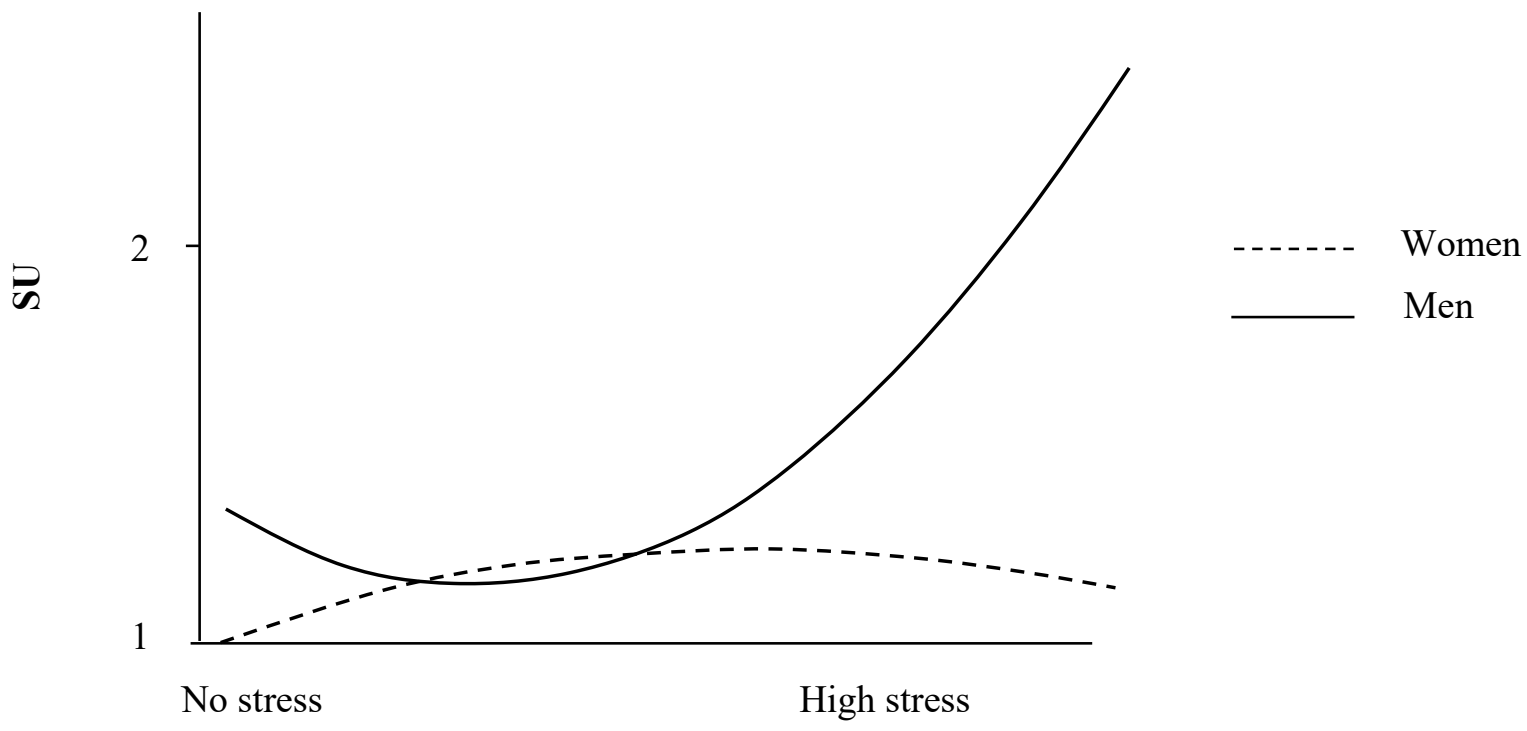

